\title{
KOVID-19 Salgını Sırasında Öğrencilerin Öğrenme Alışkanlıklarının Schur Ayrıştırma Tabanlı Dalgacık Aşırı Öğrenme Makineleri ile Tahmini
}

\author{
Dönüş Şengür \\ Fırat Üniversitesi, Eğitim Fakültesi, Ĕgitim Bilimleri Bölümü, Elazığ, Türkiye \\ dsengur@firat.edu.tr@ \\ Makale gönderme tarihi: 18.02.2021, Makale kabul tarihi: 25.05.2021
}

\begin{abstract}
Öz
KOVID-19 salgını 2019 yılında meydana gelen en kötü olaylardan biri olarak lanse edilmektedir. Salgın süreci, başta yaşam tarzımızda değişiklik yapma zorunluluğu olmak üzere birçok alanda olumsuz yönden etkilerini hissettirmiştir. Salgından en çok etkilenen alanlardan biri de eğitim olmuştur. Yüz yüze eğitim yerine uzaktan eğitim hayatımızın bir parçası olmuş ve eğitim materyallerinin hızlı bir şekilde sayısallaştırılması sağlanmıştır. Öğrencilerin daha önce deneyimlemediği uzaktan eğitim kavramı, eğitim alışkanlıklarının değişimini de beraberinde getirmiştir. Bu çalışma, yeni bir makine öğrenmesi yöntemi ile pandemi döneminde öğrencilerin öğrenme alışkanlıklarının tahmini ile ilgilidir. Daha spesifik olarak bu çalışmada, yeni bir aşırı öğrenme makinesi yaklaşımı geliştirilmiş ve bu yöntem pandemi döneminde öğrencilerin öğrenme alışkanlıklarının tahmininde kullanılmıştır. Geleneksel aşırı öğrenme makinesinde çıkış katmanı ağırlıklarının hesaplanması için Moore-Penrose matris tersi operatörü kullanılırken bu çalışmada Schur ayrıştırma kullanılarak çıkış katmanı ağırlıklarının hesaplanması gerçekleştirilmiş̧ir. Ayrıca, aktivasyon fonksiyonu olarak da dalgacık fonksiyonu kullanılmıştır. Deneysel çalışmalarda kullanılan veri seti, Hanoi'deki 420 ortaokul öğrencisinin KOVID-19 nedeniyle okul kapanışlarının ilk iki haftasında öğrenme alışkanlıkları dikkate alınarak toplanmıştır. 5-kat çapraz geçerlilik testi kullanılarak gerçekleştirilen deneylerde, \%87.41 oranında doğru tahmin yapıldığı görülmüş̧ür.
\end{abstract}

Anahtar Kelimeler: Aşırı öğrenme makinesi, dalgacık çekirdek, öğrencilerin öğrenme alışkanlıkları, Schur ayrıştırma

\section{Prediction of Students' Learning Habits with Schur Decomposition Based Wavelet Extreme Learning Machines During the COVID-19 Pandemic}

\begin{abstract}
The COVID-19 pandemic is touted as one of the worst events to occur in 2020. Many negativities occurred in our lives during the pandemic. We had to change our lifestyle. Education has been one of the areas most affected by the pandemic. Distance education has become a part of our life instead of face-to-face education and the educational materials have been digitized rapidly. Unfortunately, it was inevitable that the educational habits of the students changed. This study is about the prediction of students' learning habits during the pandemic with a new machine learning method. More specifically, in the study, a new extreme learning machine approach was developed and this method was used to predict students' learning habits during the pandemic. While the Moore-Penrose matrix inverse operator is used to calculate the output layer weights in the traditional extreme learning machine, in this study, the output layer weights are calculated using the Schur decomposition. Also, wavelet kernel is used as activation function. The data set used in the experimental studies was collected by considering the learning habits of 420 middle school students in Hanoi during the first two weeks of school closures due to COVID-19. In the experiments performed using the 5-fold cross validation test, it was observed that $87.41 \%$ of the correct predictions were obtained.
\end{abstract}

Keywords: Extreme learning machine, wavelet kernel, students' learning habits, Schur decomposition

\section{GİRIŞ}

Dünya, KOVID-19 salgınından muzdariptir ve bu durumun gelecekte de devam edeceği öngörülmektedir (World Health Organization, 2020).
Milyonlarca insana bulaşan virüs, yüzbinlerce insanın da hayatını kaybetmesine sebep olmuştur. KOVID-19 salgını ekonomi, eğitim, turizm ve enerji gibi bazı 
sektörleri önemli ölçüde etkilemiştir. Pandemi sırasında insanların çalışma, yemek yeme ve yaşam tarzları değişmiştir (Narayanan vd., 2020). Anaokullarından üniversitelere kadar milyonlarca öğrenciyi kapsayan eğitim, hayatımızın önemli bir parçasıdır ve salgın döneminde olumsuz yönde etkilenmiştir. Bahsedilen etki, öğrencilerin öğrenme alışkanlıklarını değiştirmesini de beraberinde getirmiştir. Yüz yüze eğitimin yerini uzaktan eğitim almıştır.

Pandemi sırasında öğrencilerin öğrenme alışkanlıkları ve eğitim sistemlerinin analizi ile ilgili çok az sayıda çalışma yapılmıştır. Trung vd. (2020), KOVID-19 salgını nedeniyle okulların kapanması sırasında Vietnamlı öğrencilerin öğrenme alışkanlıklarını analiz etmişlerdir. Yazarlar, sırasıyla demografik bilgiler, öğrencilerin öğrenme alıșkanlıkları ve öğrencilerin kendi kendine öğrenmeye ilişkin algılarından oluşan bir veri kümesi oluşturmuşlardır. Yazarlar anketleri yaymak için kartopu örnekleme yöntemini kullanmışlardır. Bu çalışmada sadece veri seti toplanmış ve herhangi bir analiz gerçekleştirilmemiştir. Riad vd. (2020), KOVID-19 temelli kayg1 düzeyini, koruyucu davranışları ve KOVID-19'a yönelik bilgileri değerlendirmek için araçlar geliştirmişlerdir. Sosyal ağlar aracilığıyla, Avrupa ve Çin'den gelen 215 üniversite öğrencisinden veri toplamak için kendi kendine uygulanan bir anket geliştirilmiş ve kullanılmıştır. Yazarlar, toplanan veri setini değerlendirmek için madde toplam analizi ve doğrulayıc1 faktör analizi modellerinden yararlanmışlardır. Sonuçlar, geliştirilen araçların KOVID-19'un psikolojik etkilerini ölçmek için umut verici olduğunu göstermiştir. Cao vd. (2020), KOVID-19 salgını sırasında Çin'deki tıp fakültesi öğrencilerinin zihinsel durumunu değerlendirmişlerdir. Veri setini toplamak için katılımcının kaygı bozukluk düzeylerini inceleyen 7 maddelik bir anket kullanılmıştır. Veri seti oluşturulurken 7143 öğrenci kullanılmıştır. Toplanan veri seti üzerinde çeșitli istatistiksel analizler gerçekleştirilmiş ve bazı önemli bulgular rapor edilmiștir. Odriozola-González vd. (2020), pandemi döneminde KOVID-19'un İspanya'daki üniversite öğrencileri üzerindeki zihinsel etkisini ortaya koymak istemişlerdir. Çevrimiçi bir anket kullanılarak öğrencilerin kayg1, depresyon ve stres seviyeleri ile ilgili toplanan bilgiler bir veri setine dönüştürülmüştür. Çalışmaya Valladolid
Üniversitesi'nden 2530 öğrenci katılmıştır. Toplanan veri setinin istatistiksel analizi, öğrencilerin pandemi sırasında önemli bir zihinsel etkiye maruz kaldığını ortaya koymuștur. Bitan vd. (2020), İsrail'deki KOVID-19 korku faktörünün derecesini araştırmışlardır. Katılımcıların korku, kaygı, depresyon ve stres düzeyleri bir veri setine kaydedilmiştir. Veri setinin oluşturulmasında 639 katılımcı dahil edilmiștir ve toplanan veri setinin değerlendirilmesinde iki faktörlü yapı modeline yer verilmiştir. Yazarlar cinsiyet ve kronik hastalığın KOVID-19 korkusuyla ilişkili iki önemli faktör olduğunu bildirmişlerdir. Zhang vd. (2020), KOVID19 salgınının Çinli öğrencilerin kaygı ve depresyon düzeyleri üzerindeki olumsuz etkisini değerlendirmişlerdir. Kullanılan veri seti, 66 öğrenciye uygulanan çevrimiçi bir anketle; demografik özellik, fiziksel aktivite, olumsuz duygu, uyku kalitesi ve saldırganlık seviyelerinin ölçülmesiyle oluşturulmuştur. Yazarlar, değişkenler arasındaki ilişkileri değerlendirmek için karma etki modeli kullanmış, ayrıca uyku kalitesinin aracılık etkisini de araştırmıştır. Kaparounaki vd. (2020), pandemide evde geçirilen süre içerisinde öğrencilerin psikolojik durumunu araştırmıştırlar. 1000'den fazla üniversite öğrencisine veri setini oluşturabilmek için çevrimiçi bir anket uygulanmış ve öğrencilerin depresyon, kaygı düzeyi ve intihar düşünceleri kayıt altına alınmıştır. Sonuçlar, sırasıyla kaygı, depresyon ve intihar düşüncelerinde artış olduğunu göstermiștir.

Bu çalışmada, dalgacık aşırı öğrenme makineleri (DAÖM) kullanılarak, pandemi döneminde öğrencilerin öğrenme alışkanlıklarının tahmini gerçekleştirilmiştir. Geleneksel AÖM'de çıkış katmanı ağırlıklarının hesaplanması için MoorePenrose matris tersi operatörü kullanılırken bu çalışmada Schur ayrıştırma kullanılarak çıkış katmanı ağırlıklarının hesaplanması gerçekleştirilmiştir. Ayrıca, aktivasyon fonksiyonu olarak da dalgacık fonksiyonu tercih edilmiştir. Deneysel çalışmalarda kullanılan veri seti, Hanoi'deki 420 ortaokul öğrencisinin KOVID-19 nedeniyle okul kapanışlarının ilk iki haftasında öğrenme alıșkanlıklarına dikkate alınarak toplanmıștır. Veri seti; demografik özellikler, öğrenme alışkanlıkları ve kendi kendine öğrenmeye ilişkin algılar olmak üzere üç ana değişken grubunu içermektedir. Önerilen yöntemin başarım değerlendirmesi doğruluk, duyarlılık ve özgüllük metrikleri ile sağlanmıştır. Deneysel çalışmalarda önerilen yöntemin veri seti 
üzerindeki tahmin başarımı 5-kat çapraz geçerlilik testi kullanılarak elde edilmiştir. Diğer taraftan, bilinen bazı makine öğrenmesi algoritmalarının performansları başarım yönünden karşılaştırılmıştır. $\mathrm{Bu}$ yöntemler sırası ile destek vektör makineler (DVM), k-en yakın komşular (k-EYK) ve karar ağaçları (KA) dır. Deneysel çalışmalar önerilen yöntemin, karşılaştırılan yöntemlerden daha iyi tahminler ürettiğini göstermiştir.

\section{MATERYAL VE METOT}

\section{Veri Seti}

$\mathrm{Bu}$ veri seti, Vietnam'ın Hanoi kentindeki 420 okuldaki 6-12. sınıf seviyelerindeki öğrencilerinden toplanmıştır (Trung, Hoang, Nguyen, Dinh, Nguyen, \& Pham, 2020). Veri seti, KOVID-19 nedeniyle okulların kapanmasını takip eden ilk iki haftada öğrencilerin öğrenme alışkanlıklarına odaklanmıştır. Veri seti üç ana değiş̧ken grubunu içerir:

(A) Bireysel demografik özellikler, aile sosyoekonomik durumu, okul türü ve mesleki özlemler;

(B) Öğrencilerin öğrenme alışkanlıkları ve diğer kişilerin desteği ile veya olmaksızın, okulun kapanmasından önceki ve sonraki dönemindeki toplam öğrenme saatleri;

(C) Öğrencilerin okul kapanışları sırasında kendi kendine öğrenmeye ilişkin algılar.

Ayrıca, bu süre zarfında çevrimiçi derslerin sürdürülebilirlik konularıyla entegrasyonunu ölçmek için de ankete bir soru eklenmiştir. Anket, çevrimiçi bir formatta olup toplam 920 tiklanabilecek seçenek bulunmaktadır. Onay formlarıyla birlikte toplam da 460 anket toplanmıştır. İnandırıcı olmayan cevapların bulunduğu anketler iptal edilince, nihaî veri seti 420 geçerli gözlem içermektedir. Anketlerde, doğum tarihlerini 2009 ve sonrası olarak belirten öğrencilerin cevaplarının inandırıcı olmadığı belirtilmiştir.

\section{Schur Ayrıştırma Tabanlı Dalgacık AÖM}

AÖM, tek bir gizli katman içeren denetimli bir sinir ağ1 modelidir (Alcin vd., 2014; Alcin vd., 2015; Kaparounaki vd., 2020; Zhang vd., 2020). AÖM 'de giriş-çıkış ilişkisi; giriş ağırlıkları ve ara katman biaslarının rastgele seçilmesi ve çıkış katmanı ağırlıklarının ileri geçişte Moore-Penrose tersi kullanılarak hesaplanması ile elde edilir. Basit yapısı sayesinde öğrenme yeteneği son derece hızlı ve verimlidir. Şekil 1'de AÖM yapısı gösterilmiştir.

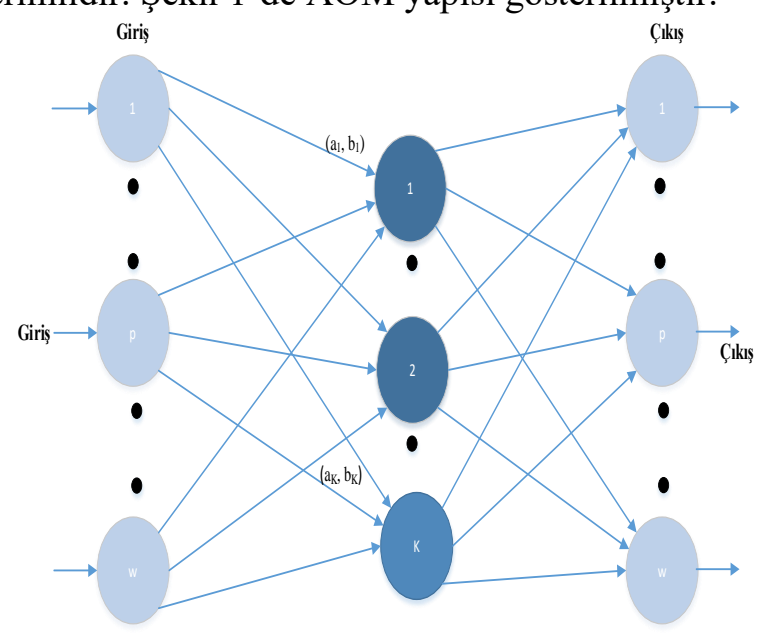

Şekil 1. AÖM yapıs1

Eğitim giriş-çıkış çiftleri $\left\{\left(x_{i}, y_{i}\right) \mid x_{i} \in R^{w}, y_{i} \in\right.$ $\left.R^{L}\right\}_{i=1}^{N}$ verilmiş olsun. Burada $N$ eğitim için kullanılacak veri boyutunu, $w$ giriş öznitelik boyutunu ve $L$ ise çıkış sınıf sayısını göstermektedir. $N \times K$ boyutundaki ara katman çıkış matrisi $H$, Denklem 1'deki gibi ifade edilir;

$$
H=\left[\begin{array}{ccc}
g\left(a_{1}^{T} x_{1}+b_{1}\right) & \ldots & g\left(a_{K}^{T} x_{1}+b_{K}\right) \\
\vdots & \ddots & \vdots \\
g\left(a_{1}^{T} x_{N}+b_{1}\right) & \ldots & g\left(a_{K}^{T} x_{N}+b_{K}\right)
\end{array}\right]_{N \times K}
$$

$a_{j}$ ve $b_{j}$ sırası ile giriş katmanı ağılıklarını ve ara katman biaslarını gösterirler. Burada $K$ ara katman hücre sayısını ve $g$ de aktivasyon fonksiyonunu gösterir. Böylece çıkış katmanı ağırlıkları $\beta$, MoorePenrose tersi $\left(H^{\prime}\right)$ kullanılarak hesaplanır. Bu durum Denklem 2'de verilmiştir.

$$
\beta=H^{\prime} Y
$$

Dalgacık aktivasyon fonksiyonu $\psi$ kullanıldığında $N \times K$ boyutundaki ara katman çıkış matrisi $H_{\psi}$, Denklem 3’teki gibi yeniden düzenlenir; 


$$
\begin{gathered}
H_{\psi}= \\
{\left[\begin{array}{ccc}
\psi\left(a_{1}^{T} x_{1}+b_{1}\right) & \ldots & \psi\left(a_{K}^{T} x_{1}+b_{K}\right) \\
\vdots & \ddots & \vdots \\
\psi\left(a_{1}^{T} x_{N}+b_{1}\right) & \ldots & \psi\left(a_{K}^{T} x_{N}+b_{K}\right)
\end{array}\right]_{N \times K}}
\end{gathered}
$$

Morlet dalgacik fonksiyonu, Denklem 4'te tanımlanmıştır (Alcin vd., 2014 );

$$
\psi(t)=\cos (1.75 t) e^{\left(-\frac{t^{2}}{2}\right)}
$$

AÖM yaklaşımına benzer olarak, çıkış katmanı ağırlıkları $\beta$ Moore-Penrose tersi yerine Schur ayrıştırma kullanılarak da hesaplanabilir (Horn ve Johnson, 1985);

$$
\beta=H_{\psi}^{\text {Schur }} X
$$

Schur ayrışımı, kare matrislerinin tersini bulmak için kullanılan etkili bir yöntemdir. Genellikle, Schur ayrışımı, Moore-Penrose ayrışımının bazı dezavantajlarını ortadan kaldırmak için kullanılmıştır (Castro-González, Martínez-Serrano, \& Robles, 2015, Léger, Deteix, \& Fortin, 2015). Kare bir matrisin $H_{\psi}$ Schur ayrışımı Denklem 6'da gösterilmiştir;

$$
Q H_{\psi}^{\text {Schur }} Q^{-1}=H_{\psi}
$$

burada $Q$ birim matrisi ve $H_{\psi}^{S c h u r}$ ise $H_{\psi}$ 'in Schur formunu gösterir ve üst üçgen matrisi olarak da bilinir. Böylece, dalgacık AÖM'nin çıkışı Denklem 7'de gösterildiği gibi elde edilir;

$$
X=H_{\psi}^{\text {schur }} \beta
$$

\section{TARTIŞMA VE SONUÇ}

\section{Deneysel Çalışmalar}

Tüm kodlamalar, NVIDIA Quadro M4000 GPU ve Intel (R) Xeon (R) CPU E5-1650 @ 3.60 GHz 64 GB bellek ile donatılmış bir bilgisayarda MATLAB ile gerçekleştirilmiştir. Deneylerde önerilen yöntemin değerlendirilmesi için 5-kat çapraz doğrulama tekniği ve ortalama doğruluk puanı kullanılmıştır. AÖM'nin parametreleri deneysel çalıșmalar sırasında sezgisel olarak seçilmiştir. AÖM'nin $C$ değeri 1000 ve gizli katman nöron sayısı ise 100 olarak belirlenmiştir. AÖM'nin daha iyi bir genelleme performansı sergilemesi için eklenen ve bir pozitif katsayı olan $C$ değişkeni, regularizasyon parametresi olarak adlandırılmaktadır. Veri setinde toplam 38 giriş (öznitelik) ve 1 çıkış bulunmaktadır. Bu girişler sırası ile cinsiyet, sınıf, derece seviyesi, okul türü, kardeş say1s1, baba ve anne meslekleri, ailenin aylık geliri, üniversiteye giriş sınav bilgisi (sayısal, sözel veya yabanc1 dil), kendini değerlendirme, İngilizce seviyesi, pandemi öncesi ve sonrasında kendi kendine öğrenme için harcanan zaman, pandemi döneminde çevrim içi alınan ders saati, pandemi döneminde bir danışman eşliğinde ve danışmansız alınan eğitim saatleri, pandemi döneminde çevrim dişı öğrenme için harcanan zaman, pandemi döneminde kendi kendine örenmenin önemi, pandemi döneminde bir danışman eşliğinde ve danışmansız alınan çevrimdışı eğitim saatleridir. Ayrıca, "Öğrenme ilerlememi temin edebilirim" ile ilgili 4 öznitelik, "Kendi kendine öğrenme faaliyetlerimin etkili olduğunu düşünüyorum çünkü" başlığı altında 7 öznitelik, son olarak da "KOVID-19'un çevrimiçi dersi sırasında, ek bilgi birikimi öğrendim" başlığı altında 5 öznitelik ve toplamda 38 öznitelik giriş olarak kullanılmıştır

Çıkış olarak "Kendi öğrenme alışkanlıklarımı sürdürürüm” başlığ1 altında bulunan 4 farklı kategori bulunmaktadır. Giriş öznitelikleri ve çıkış değişkeni tam sayı olarak sisteme verilmiştir.

Deneysel çalışmalarda öncelikle standart AÖM yaklaşımı farklı aktivasyon fonksiyonları ile kullanılmış ve elde edilen tahmin başarımları Tablo 1 'de verilmiştir.

Tablo 1. Farklı aktivasyon fonksiyonları için AÖM'nin başarımlart

\begin{tabular}{|l|l|}
\hline Aktivasyon Fonksiyonu & Doğruluk (\%) \\
\hline Sigmoid & 83.46 \\
\hline Radyal Tabanlı Fonksiyon (RTF) & 81.97 \\
\hline Hardlim & 84.44 \\
\hline Tribas & 82.71 \\
\hline
\end{tabular}

Tablo 1'de görüleceği üzere en iyi başarım \%84.44 'Hardlim' aktivasyon fonksiyonu için elde edilmiştir. 'Sigmoid' aktivasyon fonksiyonu ikinci en iyi başarımı göstermiştir. 'Sigmoid' aktivasyon fonksiyonu için elde edilen doğruluk değeri 
\%83.46'dır. Ayrıca, 'Tribas' ve RTF içinde sırası ile $\% 82.71$ ve \%81.97 doğruluk değerleri elde edilmiştir.

Tablo 2. Farklı dalgacık aktivasyon fonksiyonları için önerilen yöntemin başarımları

\begin{tabular}{|l|l|}
\hline Aktivasyon Fonksiyonu & Doğruluk (\%) \\
\hline Morlet & 87.41 \\
\hline Meksikan & 86.17 \\
\hline Meyer & 87.16 \\
\hline Shannon & 86.17 \\
\hline
\end{tabular}

Önerilen yöntemin başarım değerlendirmesi Tablo 2'de verilmiştir. Tablo 2'de görüleceği üzere, dört farklı dalgack aktivasyon fonksiyonu kullanılmıştır. Bunlar sırası ile 'Morlet', 'Meksikan', 'Meyer' ve 'Shannon' dur. En iyi başarım değeri olan $\% 87.41$, 'Morlet' dalgacik aktivasyon fonksiyonu ile elde edilirken, en kötü doğruluk değerini \%86.17 değeri, 'Meksikan' ve 'Shannon' aktivasyon fonksiyonları ile elde edilmiştir. 'Meyer' aktivasyon fonksiyonu \%87.16 doğruluk değeri ile ikinci en iyi başarımı elde etmiştir. Tablo 2 ve Tablo 1 kıyaslandığında önerilen Schur ayrışımlı dalgacık AÖM'nin, standart AÖM'den daha iyi tahminler ürettiği görülmektedir. Önerilen yöntem yaklaşık \%3'lük bir tahmin iyileştirmesi sağlamıştır.

Tablo 3 ise, Tablo 1'de verilen aktivasyon fonksiyonlarının Schur ayrışımıyla kullanılması sonucu elde edilen sonuçları içermektedir. Tablo 1 ve Tablo 3 birlikte değerlendirilirse, Schur ayrışımının, Moore-Penrose ayrışımına göre daha başarılı sonuçlar ürettiği gözlemlenmiştir.

Tablo 3. Farklı aktivasyon fonksiyonları için Schur ayrışımlı AÖM'nin başarımları

\begin{tabular}{|l|l|}
\hline Aktivasyon Fonksiyonu & Doğruluk (\%) \\
\hline Sigmoid & 85.96 \\
\hline Radyal Tabanlı Fonksiyon (RTF) & 84.17 \\
\hline Hardlim & 86.16 \\
\hline Tribas & 84.38 \\
\hline
\end{tabular}

Karşılaştırma amacı ile DVM, KA ve $k$-EYK sonuçları Tablo 4'te verilmiştir. MATLAB, sınıflandırma öğrenicisi ara yüz yazılımı kullanılarak belirtilen bu tür veri madenciliği tekniklerinin modellenmesinde kullanılır. Kullanılan veri madenciliği tekniklerinin değerlendirilmesinde 5-kat çapraz doğrulama testi kullanılmıştır ve ortalama doğruluk değerleri kaydedilmiştir. KA'nın yorumlanması kolay, uydurma için hızlı ve düşük bellek kullanımı gibi birçok olumlu özelliği vardır. Ancak uygulamaya bağlı olarak düşük tahmin doğruluğu elde edebilirler. KA yapısında, maksimum bölünme sayısı 4 olarak belirlenmiştir. DVM algoritması, bir sınıfin veri noktalarının diğerlerinden ayrılmasının garanti edildiği en iyi hiper düzlemi arar. Uygulamada, doğrusal DVM algoritması kullanılmıştır. $k$-EYK sınıflandırıcıları genellikle düşük boyutlarda yüksek tahmin doğruluğuna sahiptir. Bu, $k$-EYK sınıflandırıcılarının bir avantajı olarak görülebilir, yüksek bellek kullanımı ve yorumlanması kolay olmayan özellikler onları dezavantajlı hale getirir. $k$-EYK tekniğinde komşu $k$ değeri 1 olarak seçilir.

Tablo 4. Önerilen yöntemin diğer yöntemler ile başarım karşılaştırması

\begin{tabular}{|l|l|}
\hline Yöntem & Doğruluk (\%) \\
\hline KA & 80.2 \\
\hline DVM & 74.3 \\
\hline$k$-EYK & 63.1 \\
\hline Önerilen Yöntem & 87.41 \\
\hline
\end{tabular}

Tablo 4'te görüleceği üzere KA, DVM ve k-EYK yöntemleri sıras1 ile $\% 80.2, \% 74.3$ ve $\% 63.1$ gibi başarım değerleri üretmişlerdir. Burada en başarılı sonuç olan \%87.41 değerini görüldüğü gibi önerilen yöntem üretmiştir. KA yöntemi ikinci en iyi doğruluk değerini üretirken, en kötü doğruluk değeri de k-EYK yöntemi tarafindan üretilmiştir.

\section{SONUÇLAR}

Pandemi hayatımızın her alanını birçok yönden olumsuz etkilemiş ve etkilemeye de devam etmektedir. Bu alanlar biri de eğitim alanıdır. Salgın sebebiyle milyonlarca öğrenci eğitim hayatına evden devam etmek zorunda kalmıştır. $\mathrm{Bu}$ durum öğrencilerin öğrenme alışkanlıklarında değişikliklere neden olmuştur. $\mathrm{Bu}$ çalışma, pandemi döneminde öğrencilerin öğrenme alışkanlıklarının dalgacık aşırı öğrenme makineleri kullanılarak tahmini ile ilgilidir. Schur ayrıştırma ve dalgacık aktivasyon fonksiyonu ile daha gürbüz bir AÖM yapısı üretilirmiş ve 420 örnek içeren bir veri setinde deneysel çalışmalar yapılmıştır. Deneysel çalışmalarda önerilen yöntemin veri seti üzerindeki tahmin başarımı 5-kat çapraz geçerlilik testi kullanılarak elde edilmiştir. Deneysel çalışmalarda hedeflenen tahminin \%87.41 oranında 
doğru yapıldığı görülmüştür. Ayrıca önerilen yöntemin başarımı bilinen bazı makine öğrenmesi yöntemlerinin başarımları ile kıyaslanarak, önerilen yöntemin etkinliği ortaya konulmuştur.

\section{ÇIKAR ÇATIŞMASI BEYANI}

Yazar/ Yazarlar bu makale ile ilgili herhangi bir çıkar çatışması bildirmemektedir.

\section{ARAŞTIRMA VE YAYIN ETİĞİ BEYANI}

Yazar/Yazarlar bu çalışmanın araştırma ve yayın etiğine uygun olduğunu beyan eder.

\section{KAYNAKLAR}

Alcin, O. F., Sengur, A. and Ince, M. C. (2015). "Forwardbackward pursuit based sparse extreme learning machine." Journal of The Faculty of Engineering and Architecture of Gazi University 30(1), 111-117.

Alcin, O. F., Sengur, A., Ghofrani, S., \& Ince, M. C. (2014). GA-SELM: Greedy algorithms for sparse extreme learning machine. Measurement, 55, 126132.

Bitan, D. T., Grossman-Giron, A., Bloch, Y., Mayer, Y., Shiffman, N., \& Mendlovic, S. (2020). Fear of COVID-19 scale: Psychometric characteristics, reliability and validity in the Israeli population. Psychiatry Research, 113100.

Cao, W., Fang, Z., Hou, G., Han, M., Xu, X., Dong, J., \& Zheng, J. (2020). The psychological impact of the COVID-19 epidemic on college students in China. Psychiatry research, 112934.

Castro-González, N., Martínez-Serrano, M. F., \& Robles, J. (2015). Expressions for the Moore-Penrose inverse of block matrices involving the Schur complement. Linear Algebra and its Applications, 471, 353-368.

Horn, R.A. \& Johnson, C.R. (1985). Matrix Analysis. Cambridge University Press. ISBN 0-521-38632-2.

Kaparounaki, C. K., Patsali, M. E., Mousa, D. P. V., Papadopoulou, E. V., Papadopoulou, K. K., \& Fountoulakis, K. N. (2020). University students' mental health amidst the COVID-19 quarantine in Greece. Psychiatry Research, 113111.

Léger, S., Deteix, J., \& Fortin, A. (2015). A MoorePenrose continuation method based on a Schur complement approach for nonlinear finite element bifurcation problems. Computers \& Structures, 152, 173-184.

Narayanan, L., Pandit, M., Basu, S., Karmakar, A., Bidhan, V., Kumar, H., \& Brar, K. (2020). Impact of lockdown due to COVID-19 outbreak: Lifestyle changes and Public Health Concerns in India.

Odriozola-González, P., Planchuelo-Gómez, Á., Irurtia, M. J., \& de Luis-García, R. (2020). Psychological effects of the COVID-19 outbreak and lockdown among students and workers of a Spanish university. Psychiatry Research, 113108.

Riad, A., Huang, Y., Zheng, L., \& Elavsky, S. (2020). COVID-19 Induced Anxiety and Protective Behaviors During COVID-19 Outbreak: Scale Development and Validation. medRxiv.

Trung, T., Hoang, A. D., Nguyen, T. T., Dinh, V. H., Nguyen, Y. C., \& Pham, H. H. (2020). Dataset of Vietnamese student's learning habits during COVID19. Data in Brief, 105682.

World Health Organization. IHR Emergency Committee on Novel Coronavirus (2019-nCoV) (2020).

Zhang, Y., Zhang, H., Ma, X., \& Di, Q. (2020). Mental Health Problems during the COVID-19 Pandemics and the Mitigation Effects of Exercise: A Longitudinal Study of College Students in China. International Journal of Environmental Research and Public Health, 17(10), 3722. 